curring in the above case is difficult to correlate. Before the appearance of rash on the face the patient gave a history of sore throat and joint pains, and as the throat swab and the E.N.T. reports were both negative it is suggested that initially she had subclinical tubercular infection of her tonsils which, when the patient's resistance was lowered after the pelvic operation, spread to the cervical glands and later by the blood stream causing miliary changes in kidneys, spleen and intestinal glands as observed at necropsy. It is difficult to understand why the lungs escaped this miliary invasion. Lupus erythematosus of the face can be regarded as an allergic response in the collagen tissue of the face and the harmful agent, as subsequent course showed, may have been a tubercular focus. This allergic response at first remained localized to face but as the tuberculosis spread the allergic response also became more marked, causing more advanced joint changes and later culminating into periarteritis nodosa affecting the small bowel and producing the clinical picture of acute abdomen. The other possibility is that the allergic response is due to an unknown allergen and the finding of tuberculosis is just a coincident. Whatever may have been the cause of the original illness, this case clearly emphasizes the point which MacKenna (195I) makes in his excellent review on the pathogenesis and treatment of all forms of lupus erythematosus, that unless the etiology of the disease is well established no treatment can be of lasting value and that perhaps more than one factor is responsible for this dreaded malady.

\section{Summary}

A case presenting an unusual combination of lupus erythematosus, periarteritis nodosa and miliary tuberculosis, not hitherto recorded, is discussed in the light of our present knowledge of the etiology of lupus erythematosus.

I wish to express my thanks to Dr. J. S. Marr for referring this patient to me.

\section{BIBLIOGRAPHY}

DUFF, G. L. (1948), Canad. Med. Ass. F., 58, 317.

$\mathrm{ORR}, \mathrm{H}$. (1950), Canad. MAed. Ass. Ұ., 62, 432 .

MACKENNA, R. M. B. (1951), The Medical Annual, 16r.

\title{
AUTO-REDUCTION EN MASSE OF AN INGUINAL HERNIA
}

\author{
By RoBert W. BaIlie, M.B., F.R.C.S.(Edin.) \\ Lately Senior Surgical Registrar, Sefton General Hospital, Liverpool
}

Reduction en masse of a strangulated hernia is now a very rare occurrence, but one gains the impression from the literature that it was more common during the last century, though Corner and Howitt, in a report in 1908 on investigations of the records of St. Thomas's and St. Bartholomew's Hospitals, found only five cases in 1,618 strangulated herniae, an incidence of 0.3 per cent. As taxis was then very often employed in the reduction of strangulated herniae ( 14 per cent. of cases of strangulated hernia admitted to St. Thomas's Hospital ' escaped operation by undergoing reduction,' Corner and Howitt), a higher incidence of reduction en masse would be expected.

Berger ( 1876$)$ gave the incidence of strangulation as 2.5 per cent., and hence the incidence of reduction en masse would be 0.0075 per cent. of all herniae. In a review of 12,000 cases, Eliason (1921) found no such case, but Nason and Mixter (1935), on the other hand, found three cases of this type in a group of 73 cases of strangulated hernia. strangulated hernia reduced en masse has been briefly summarized by Casten and Bodenheimer (I94I) as follows:-

I. An inguinal or femoral hernia has been present for several years and may have been operated on previously.

2. This hernia has become incarcerated previously on several occasions but has always been reduced by manipulation.

3. The last reduction was accomplished with more difficulty and was accompanied by pain.

4. The symptoms of intestinal obstruction do not subside as expected or subside for only a brief interval. (This interval, in fact, is not necessarily very brief being, apparently, two months in one of Walsham's cases.)

The continuation of symptoms of intestinal obstruction after the apparent reduction of a strangulated hernia is very suggestive of reduction en masse and often there is absence of local signs of the disorder though a tumour may be palpable 
in the lower abdomen or above the internal inguinal ring.

\section{Case Report}

The present case is described because it shows an added complication which I cannot find previously reported in the literature.

A male patient, aged $5^{6}$ years, was admitted to Sefton General Hospital on May 9, 1950, and gave the following history: A left inguinal hernia had been present for about 20 years and was easily reducible, descended into the scrotum and, more recently, had been controlled by a truss.

Three days before admission he had developed pains across the lower abdomen and tenderness in the hernial sac. He reduced the hernia easily and the pains disappeared soon afterwards.

On the afternoon of the day of admission, pain developed suddenly in the left iliac fossa which doubled him up and was followed in about I $_{5}$ minutes by vomiting. The pain was griping in character and further vomiting occurred. The bowels opened once after the onset of pain and the motion was formed.

Examination revealed the patient to be in fair general condition and not distressed. His temperature was $98^{\circ} \mathrm{F}$., pulse rate 60 and respirations 24 per minute. The abdomen was relaxed and non-tender; the left superficial inguinal ring was empty but proximal to it, in the position of the deep inguinal ring, was a deeply placed, tender swelling. Rectal examination was negative.

A diagnosis of strangulated hernia of properitoneal or interparietal type was made.

Operation was performed under pentothal, curare and closed circuit oxygen and ether (Dr. I. Emerson).

A left inguinal incision was used and after incising the external oblique aponeurosis, the internal oblique muscle was retracted strongly upwards and outwards to expose the sac of the hernia. This was found to be lying extraperitoneally, slightly above and lateral to the usual position of the deep inguinal ring. All attempts to find the neck of the sac were unsuccessful as the walls of the sac appeared to become invaginated or infolded in that region. On opening the sac near its fundus and dividing the wall in the general direction of the neck, it was found that the proximal part or neck of the hernial sac had apparently been invaginated or intussuscepted into the more distal part of the sac. The constricting mechanism was formed by the inverted walls of the latter or the neck of the latter, which had progressed by a form of intussusception to lie outside and compress the entering funnel of peritoneum. When the constricting mechanism was divided, the sac unfolded easily. It was then found to be an indirect sac containing

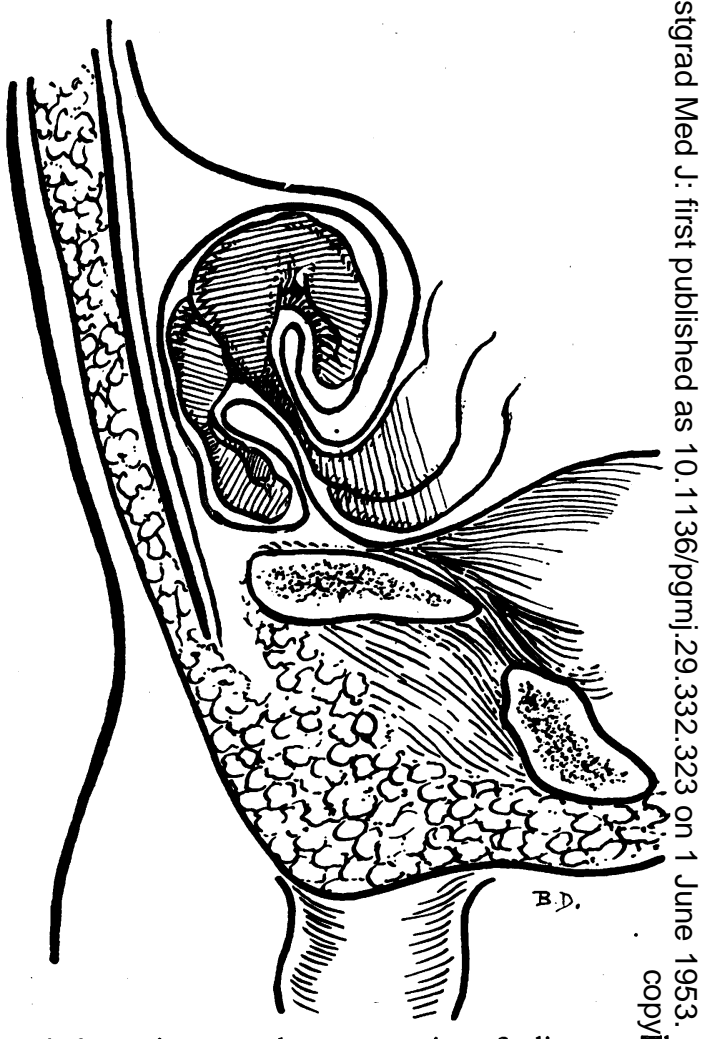

Saggital section to show operation findings. T्रेhe hernial sac lies in the properitoneal position ang contains strangulated bowel. The original necs has been invaginated into the more distal part of the sac, the constricting mechanism being now th inverted walls of the sac or the neck of the sas which had progressed by a form of intussusception to lie outside and compress the entering funnel peritoneum.

strangulated small bowel which was quite viable

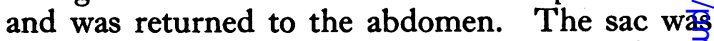
then transfixed through the neck, ligatured, excised and a Willys Andrew's modification of the Bassini repair carried out.

The post-operative course was uneventful apa from some chest infection and the patient was discharged on the r6th post-operative day. He was seen at the out-patient clinic three months lated and there was no sign of recurrence of his hernia

Aetiology and Mechanism

In discussing the mechanism of reduction masse, Pearse (193I) postulates three main type\&, viz.:

Type I. The conversion of an inguino-pre peritoneal hernia into the properitoneal type. क

Type 2. Change of the sac to the properitoneall position by its separation from its surroundin tissues without relief of the obstruction at its nect. 
Type 3. Removal of the strangulated bowel from the inguinal to the properitoneal pouch of an inguino-properitoneal hernia without dislocating the inguinal sac.

Types $I$ and 3 above depend for their occurrence on the presence of a preformed properitoneal sac, and Halsted considered the important factors in producing this were: The presence of a badly fitting truss closing the external ring but not the inguinal canal, the repeated and vigorous attempts at reducing an inguinal hernia with a narrow neck to its sac and, finally, the presence of congenital defects such as undescended testicle or congenital properitoneal diverticulum.

Casten and Bodenheimer (I94I) say that the relationship between (a) the internal abdominal ring and (b) the neck of the sac is the important factor in the occurrence of reduction en masse. Attempted reduction of a strangulated inguinal hernia will be:

I. Complete and satisfactory if the constrictions at (a) and (b) are neither very tight.

2. If, on the other hand, both are tight, no reduction will occur.

3. Finally, if (b) has an unyielding constriction while (a) is lax, reduction en masse will occur.

In the case reported here the neck of the sac was narrow but not unduly so and it is difficult to understand how the intussusception occurred. It seems possible that the inguinal sac of an inguinoproperitoneal hernia could become intussuscepted into the properitoneal part of the sac, but this did not seem to be the case on this occasion. It seems much more likely that the sac was displaced to lie around the rather rigid neck which then gradually became invaginated into the sac.

As most of the cases described in the literature were approached trans-abdominally, it is possible that the occurrence of such a secondary complication, especially in minor degree, may have been missed in other cases as it would not be very obvious when viewed from the abdominal side and might be reduced by manipulation of the neck of the sac before being recognized.

In a limited review of the literature since Pearse's article (I93I), it is interesting to note that the mortality rate has fallen from 44.6 per cent. in his cases to 15.3 per cent. in a series of 13 cases (Casten and Bodenheimer, Chapple, Coles, Cooley, Crowe, Druckerman, Nason and Mixter, five cases, Wolfe and the present case). In these cases, reduction or attempted reduction by a doctor only occurred twice as against 6o per cent. of times in Pearse's cases, an indication of the lessened tendency to use taxis in the treatment of strangulated inguinal and femoral herniae.

\section{Summary}

A case of auto-reduction en masse of a strangulated inguinal hernia, showing a new complication, namely a secondary intussuception of the neck of the displaced hernial sac into the rest of the sac, is recorded.

The various theories of mechanism of occurrence of reduction en masse are briefly discussed and the probable mechanism in the present case indicated.

\section{BIBLIOGRAPHY}

CASTEN, D., and BODENHEIMER, M. (194I), Surg., 9, 560. CHAPPLE, C. F. (1950), Brit. med $\mathcal{F}$., i, 286.

COLES, J. S. (1941), F. Mt. Sinai Hosp., N.Y., Sept.-Oct., 178. CORNER, E. M., and HOWITT, A. B. (1908), Ann. Surg., 47, 573 COOLEY, G. G. (1942), Brit. F. Surg. 29, 352.

CROWE, G. G. (1943), Lancet, i, 517

DRUCKERMAN, L. J. (1938), $\%$. Mt. Sinai Hosp., N.Y., 4, 457. TURNER, G. GREY'(1903-4), 'Nörthümberland and Durham Medical $\mathcal{F}$., 222.

NASON, L. H., and MIXTER, C. G. (1935), F. Amer. Med. Assoc., 105, 1675.

PEARSE, H. E (193I), Surg. Gynec. Obstet., 53, 822.

WALSHAM, W. J. (1901), Brit. med. F., i, 691 .

WOLFE, H.'R. I. (1939), Brit. F. Surg., 27, 42 I.

\section{INTRODUCTION OF DIONOSIL OILY}

Glaxo Laboratories, Ltd., announce the introduction of 'Dionosil Oily,' a contrast medium for bronchography which supplements the original 'Dionosil ' aqueous suspension. 'Dionosil Oily' is a 50 per cent. suspension of propyliodone in arachis oil. The iodine content is about 30 per cent.; in $20 \mathrm{cc}$. there are about $6 \mathrm{~g}$. of iodine. 'Dionosil Oily' may be employed for bronchography by all the customary procedures without significant modification of technique. With both the aqueous and oily forms, the contrast agent is completely absorbed and eliminated within a few days.

A suitable volume of 'Dionosil Oily' is $0.75 \mathrm{cc}$. to I cc. for each year of age, up to a maximum of 12 to $18 \mathrm{cc}$. for the average adult.
'Dionosil' and 'Dionosil Oily' are available in vials containing an overage to permit average withdrawal of $20 \mathrm{cc}$.

William R. Warner \& Co., Ltd., Power Road, London, W.4, announce the introduction of Tyrosolven, a. new antibiotic-analgesic throat lozenge for the treatment of mouth and throat infections.

Tyrosolven lozenges are composed of the antibiotic tyrothricin and a local anaesthetic, benzocaine, possessing marked bacteriostatic and bactericidal properties combined with a tyrothricin solvent in a pleasantly flavoured lozenge base.

Tyrosolven lozenges are available in tubes of 20 and in dispensing packs of 250. 